\title{
Spatial Variability and Relationship of Spectral Reflectance and Growth Status to Corn Canopy in the Different Growth Stage
}

\author{
Shuqiang Li \\ School of Electronic and Information Engineering, South China University of Technology, Guangzhou 510640, Guangdong, \\ China
}

\begin{abstract}
In order to finding a convenient way of acquiring chlorophyll spatial distribution in different growth stage, the canopy reflectance of corn seedling and the relationship between the spectral reflectance of corn seeding and growth were analyzed. The results indicated that the spatial variability of the canopy chlorophyll content of corn was variant in different growth stages. The variance was not reformed over the growth stages. There are not high correlations between chlorophyll content and RVI. The chlorophyll content showed better correlations on with NDVI and with reflectance of $550 \mathrm{~nm}$. Focus on the relationship between reflectance of $550 \mathrm{~nm}$ and chlorophyll, it can be found that the correlation coefficient was about $0.88 \sim 0.69$. It reached highest before five leaves. It showed that the reflectance on $550 \mathrm{~nm}$ may characterize the amount of chlorophyll. It could help to guide the fertilization during the growth stages of corn.
\end{abstract}

Keywords—corn; seedling stage; spectral characteristic; GPS; precision fertilizer

\section{INTRODUCTION}

The growth stage of corn is composed with three periods: seeding stage, heading stage and flowering to maturity stage. The seeding stage, during sowing date and shooting stage, is the most important stage of absorbing nutrients. So It has significance of providing the basis for variable management to accurately grasping distribution information of the corn.

Chlorophyll is the most important detection to reflect the growth status of corn. There were two ways to grasp the content of chlorophyll. The first way was using the SPAD-520 which had proven to be useful tools for rapid, non-destructive assessment of chlorophyll and nutrient status in various agricultural. But the shortage was the result could not reflect the chlorophyll level on the filed range. As to corn, it was effective way to manage the fertilization by grasping the chlorophyll as a whole area. The second way was typical canopy leaves were chosen as objects. In the lab, their chlorophyll and spatial characters would be analyzed. The result of canopy chlorophyll content is accurately but less realtime. The Normalized Difference Vegetation Index (NDVI) is an important vegetation index, widely applied in research on Growth status of vegetation, productivity and other biophysical, biochemical characteristics of sensitive and in detection of land use cover, vegetation cover density assessment, crop identification and crop production forecasting, etc. The analysis of NDVI data of canopy leaves and chlorophyll content and spatial distribution trends shows that the NDVI data of canopy are influenced by environmental factors such as the surface coverage during the period of reviving. It is necessary to find some method of Accessing to chlorophyll variation of corn growth characteristics in a field scale. It will be helpful to provide the effective support tools of managing the fertilization during heading stage. Firstly, the canopy multi spectral reflectance would be measured by advanced spectroscopy. Then the research focusing on the relationship between the spatial variation of nutrients and reflectance would make the foundation on the way of detection the growth of corn by ground-based remote sensing.

\section{MethodolOgy AND METHODS}

\section{A. Methodology and Experiment Area}

The experimental equipment was SHIMADZU UV-2450 Spectrophotometers. UV-2450 was used to measure canopy spectrum of corn on different growth stage. After that, the unfolding leaf samples were collected and the chlorophyll content of the leaves was analyzed. First the leaves were treated by ethanol and acetone to obtain solution. And then the chromatists of the solution was measured by a 751 UV visible spectrophotometer to calculate the chlorophyll content of the leaves. The test data was processed, and the values of the canopy spectrum and chlorophyll content were combined with GPS location information. Surfer 8 with the Kriging interpolation method (Golden Software Company) was used to generate the spatial distribution. These maps would show the growth distribution of corn during the different growth stage.

The field experiments were executed in April-June 2017 in Shang zhuang Base for Precision Agriculture, China. The base is located in Shang zhuang Town, Haidian District of Beijing, north latitude $40^{\circ}$ east longitude $116^{\circ}$ in the vicinity. The length of the selected experimental area was about $104 \mathrm{~m}$, width of $24 \mathrm{~m}$. The entire region was divided into 27 cells, and each cell was marked out the border with pole. The sampling points of each cell were random set and then were marked by flags. Using a sub-cm differential GPS system, the positioning information of the borders and sampling points were measured. The variety of the experimental summer corn was Zheng-dan 958, and the planting was performed in March of 2017. Since 
the temperature was lower in this spring, the beginning of the experiment was the period of the early turning green.

\section{B. Canopy Spectral Data Collection}

Around the GPS point, the frondescence samples were collected and the chlorophyll content of these leaves was analyzed by UV-2450 in laboratory. SHIMADZU UV-2450 Spectrophotometers with wide ranging samples, including organic and inorganic compounds, biological samples like DNA and enzymes, as well as special measurements on optical materials. According to select the appropriate frequency, curves of canopy spectrum would be measured quickly.

\section{Canopy Chlorophyll Data Collection}

After each instrument measurement, leaf samples from testing plants were collected for measuring chlorophyll content in the laboratory, to do so, $0.4 \mathrm{~g}$ leaf sample was filled in test tubes with $25 \mathrm{ml}$ solution mixed acetone and ethanol in a 2:1 ratio. After placing the tubes in a darkroom for 24 hours to dissolve the chlorophyll in the solution, the chlorophyll contents of those processed samples were measured using UV2450 spectrophotometer. Based on results on $645 \mathrm{~nm}$ and $663 \mathrm{~nm}$, the real content of chlorophyll of each sample could be calculated as follows:

$$
\begin{gathered}
C_{a}=12.72 A_{663}-2.59 A_{645} \\
C_{b}=22.88 A_{645}-4.67 A_{663} \\
C_{t}=C_{a}+C_{b}
\end{gathered}
$$

Where $A_{663}$ and $A_{645}$ represented the reflectivity on $663 \mathrm{~nm}$ and $645 \mathrm{~nm} . C_{t}$ represented the real content of chlorophyll each sample.

\section{RESULTS AND DisCUSSION}

\section{A. Spatial Distribution of Chlorophyll at the Seeding Stage}

There were four experiments during the seeding stage. The different spatial distribution of chlorophyll was showed in Figure I.

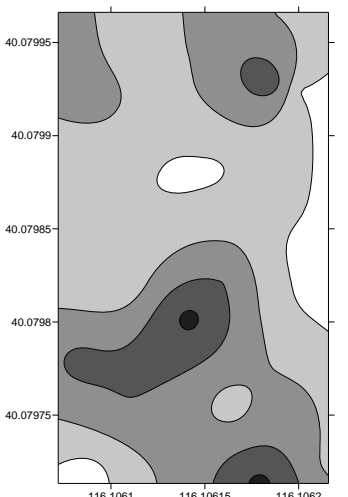

(a) stage of three leaves

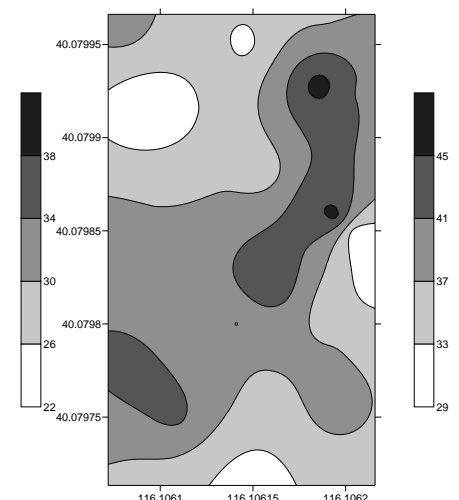

(b)stage of four leaves

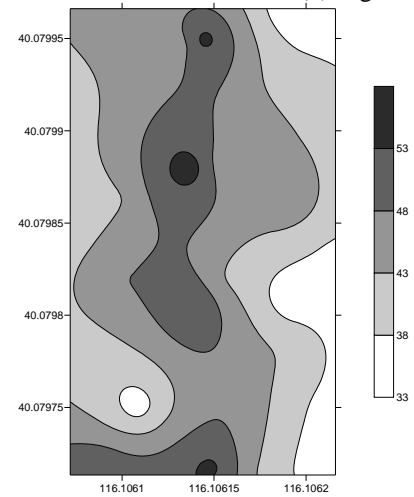

(c) early stage of five leaves

FIGURE I. THE SPATIAL DISTRIBUTION OF CORN SEEDLING CHLOROPHYLL

Figure I shows the corn chlorophyll distribution in different regions during the experimental growth period. The gray level was used to indicate the chlorophyll content. It was obviously to see the reviving of the overall low level and a larger value changes in chlorophyll content. it had a wide range of values and uneven spatial distribution in chlorophyll content. This is mainly because fertilization is not uniform before experiment, the corn seedling had growth of different abilities, different ability to absorb nutrients. In the stage of three leaves, the overall chlorophyll levels were significantly lower and the large spatial variability. To the early stage of five leaves, the chlorophyll levels throughout the test area were at a higher level of basic, uniform distribution over the other two phases. This shows that the precision management of corn should be conducted in stage of three leaves and stage of four leaves, which were uneven distribution and low chlorophyll. Accordin the spatial distribution of chlorophyll content of corn, it should choose a reasonable management strategy, which can increase the ch g tolorophyll content and minimize the spatial difference. It would provide adequate supply of nutrients for the growth of corn in the stage of three leaves and four leaves.

The average results are shown as Table I based on the different growing stages of the corn. 
TABLE I. THE AVERAGE OF CHLOROPHYLL (MG/L)

\begin{tabular}{|c|c|c|c|}
\hline Growth stage & $\begin{array}{c}\text { Stage of } \\
\text { three leaves }\end{array}$ & $\begin{array}{c}\text { Stage of } \\
\text { four leaves }\end{array}$ & $\begin{array}{c}\text { Early stage } \\
\text { of five } \\
\text { leaves }\end{array}$ \\
\hline Average chlorophyll & 29.85 & 37.04 & 43.61 \\
\hline
\end{tabular}

Table I showed the trend of average chlorophyll content of different stage. It was observed that trend raised from the stage of three leaves to the stage of five leaves and the rate of chlorophyll was raised slowly. The phenomenon indicates that the nutrient of soil has been exhausted on the period of the stage of five leaves. There are no enough nutrient to supply the corn's growth. It was time to fertilizer on the period of the stage of five leaves. These results were same as that showed in Figure I. But the Figure I showed the spatial distribution in chlorophyll content and the Table I showed the average chlorophyll trend change during the growth stage. It would be very significant to combine these two ways to show the status of growth of corn from three leaves stage to five leaves stage. That would be given the more accurate guide of fertilization.

\section{B. The Comparing of Spectral Reflectance of Different Stage of Seeding Period}

The curve of reflective between 400nm and 850nm showed as Figure II. The data of curve were test by SHIMADZU UV2450 .

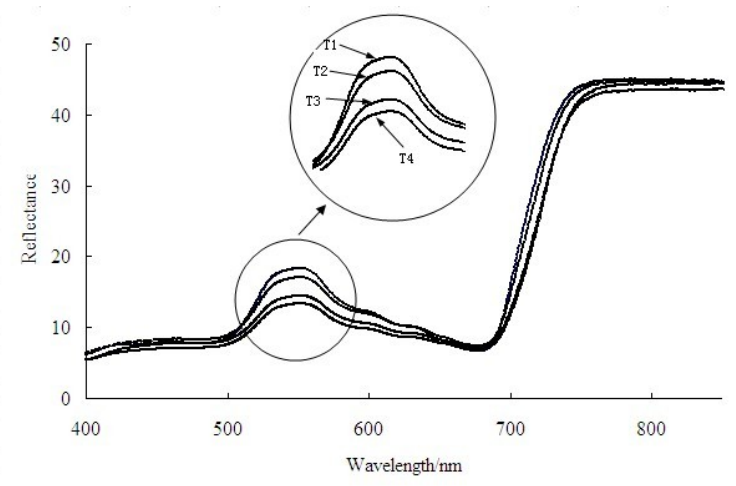

FIGURE II. THE CANOPY REFLECTANCE OF CORN SEEDLING

As Figure II showed, the curves of wave lengths from 400 to $850 \mathrm{~nm}$, which is include the visible band (400 700) and the near-infrared (NIR) band (700 850), were selected to analyze the canopy spectral characteristics. It had a lower reflectance between 400 and 700nm and higher between 700 850nm. There was a sharply rise between 700 750nm. Many tests had the same trend. At 550nm , the top of curve dropped of during the growing period of corn. Between 700 850nm, the curve of reflectance showed the same trend and little difference. So the research at reflectance spatial around 550nm could helping on grasping the different period the chlorophyll spatial.

\section{The Research on Reflectance Spatial at 550nm}

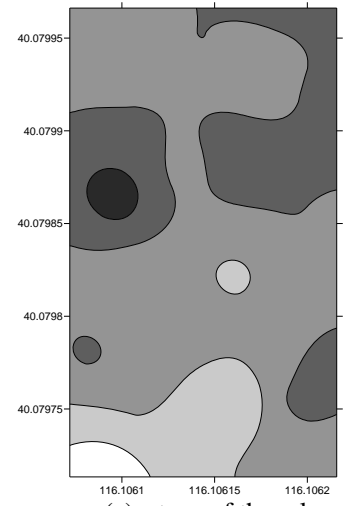

(a) stage of three leaves

(c) early stage of five leaves

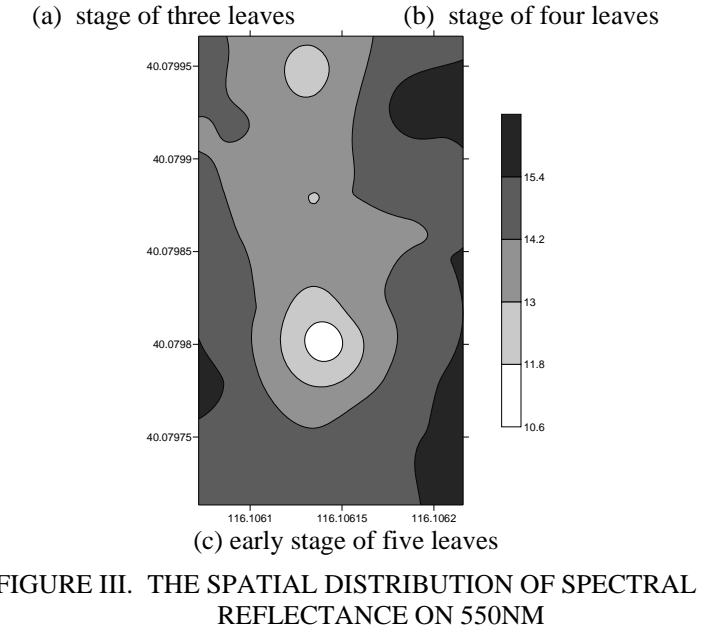

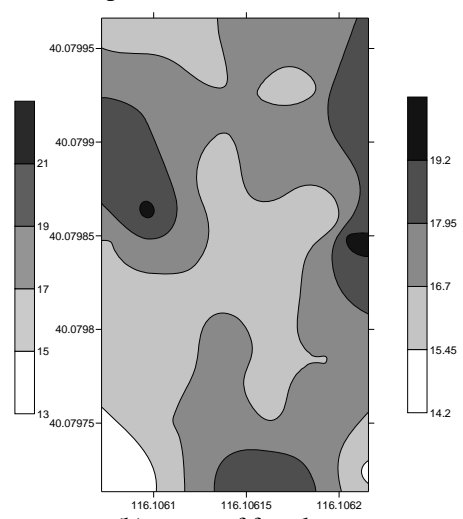

(b) stage of four leaves
Figure III showed the spatial of reflectance at 550nm about four tests. The lighter color indicated where the reflection was higher. The deeper color means where the reflectance was lower. It can be seen from the Figure III that there was the higher reflectance of the canopy leaves at the early maize. It meant the corn absorbed the nutrients less and the chlorophyll of canopy leaves was lower level on the field level at this period. Fig III (c) showed the reflectance of canopy leaves was lowest in the test period. It indicated that there was the lowest reflectance during the maize period. The reason was the corn absorbed the nutrients adequately and the content of chlorophyll in the canopy leaves was higher than other parts of maze period. It also can be seen from the figure III that the chlorophyll spatial was uneven. The reason was the corn absorbed nutrients to supply growth mainly from the soil which had the differently fertilized before planting. Overall, the reflectance was gradually decreased. This shows that the research on reflectance value of 550nm and spatial distribution could grasp the spatial distribution of chlorophyll and understand the growth status of corn.

\section{Correlation between Reflectance at the Characteristic Band and Spatial of Chlorophyll Value}

The average values of the canopy chlorophyll of each row and the reflectance of 550nm of canopy were correlation. The correlation analysis between vegetation index (such as NDVI、 
RVI) and chlorophyll would be made. The Table II showed these:

TABLE II. CORRELATION AND VEGETATION INDEX OF DIFFERENT STAGE

\begin{tabular}{|c|c|c|c|}
\hline Growth stage & $\begin{array}{c}\text { Stage of } \\
\text { three leaves }\end{array}$ & $\begin{array}{c}\text { Stage of } \\
\text { four leaves }\end{array}$ & $\begin{array}{c}\text { Early stage of } \\
\text { five leaves }\end{array}$ \\
\hline NDVI & 0.712 & 0.715 & 0.720 \\
\hline RVI & 0.146 & 0.156 & 0.163 \\
\hline $\begin{array}{c}\text { Reflectance of } \\
\text { 550nm }\end{array}$ & -0.73 & -0.74 & -0.88 \\
\hline
\end{tabular}

Table II showed that there was less correlation between chlorophyll of canopy leaves and RVI. There was higher correlation between chlorophyll and NDVI and reflectance of $550 \mathrm{~nm}$. The most stable correlation about NDVI. The correlation value was about $0.71 \sim 0.73$ over four growth stages. That would be valuable indicators for monitoring the growth status of corn. There was a negative correlation between the average chlorophyll and reflectance of $550 \mathrm{~nm}$. The value was about $-0.88 \sim-0.69$. So it obviously could be seen that the absolute value of correlation increased gradually with the growth stage continued. The value was maximum about the early stage of five leaves. The fact meant that the reflectance about $550 \mathrm{~nm}$ of early stage of five leaves indicated the chlorophyll of canopy leaves accurately. It might be due to the peak of leaf growth at this period. The corn absorbed the nutrients from environment substantially for the energy reserves on the subsequent phases. The chlorophyll content was higher and the absorption spectrum was the most obvious. The correlation value tended to decrease and the growth status of leaves was reduced. So the best fertilization period was the stage of five leaves. According to Table III, the reflectance of $550 \mathrm{~nm}$ was the best indicator for monitoring the growth status of corn. It was the better idea that the precision fertilization was arranged at this stage.

\section{CONCLUSION}

This paper researched on the spatial distribution about chlorophyll at the different growth stage of corn maize. The characteristics of reflectance curve about canopy leaves would be analyzed. There were some discussion on the correlation between chlorophyll and reflectance at $550 \mathrm{~nm}$. The researches drew some conclusions:

(1) The spatial distribution of chlorophyll on different growth stage was uneven on the test field level. This characteristic would not be changed on the whole growth stage. That meant the analysis about the spatial distribution of chlorophyll would indicate the growth status of corn and the chlorophyll spatial distribution. That might provide the effective decision on precision fertilization.

(2) The analysis on correlation between the vegetation index (NDVI/RVI) and chlorophyll was made. The results showed there were lower correlation coefficient between RVI and chlorophyll while higher correlation coefficient between NDVI and reflectance at $550 \mathrm{~nm}$. So these were the better indicators about reflectance at 550nm and NDVI.
(3) The research on the correlation between the reflectance at $550 \mathrm{~nm}$ and chlorophyll would show that there was obviously the negative correlation. The negative correlation values about $-0.88 \sim-0.69$. The absolute value reached highest at the period of early stage of five leaves. It showed that the reflectance at $550 \mathrm{~nm}$ could indicate the chlorophyll value of canopy leaves. It would be helpful for precision fertilization for the maize stage of corn.

\section{REFERENCES}

[1] Bove J. M. Journal of Plant Pathology, 2006, 88(1): 7-37.

[2] Li X., Lee W. S., Li M., et al. Computers and Electronics in Agriculture, 2012, 83: 32-46.

[3] Choi D., Lee W. S., \& Ehsani R. St. Joseph, Mich.: ASABE, 2013.

[4] Wang N, \& Trivedi P. Phytopathology, 2013, 103(7): 652.

[5] Li W., Abad J. A., French-Monar R. D., et al. Microbiol. Methods, 2009, 78: 59-65.

[6] Lorente D., Aleixos N., Gómez-Sanchis J., et al. Food Bioprocess Technol, 2012, 5:1121-1142.

[7] Sankaran S., \& Ehsani R. Crop Prot., 2011, 30(11): 1508-1513.

[8] Sankaran S., Mishra A., Maja J. M., et al. Computers and Electronics in Agric., 2011, 77(2): 127-134.

[9] Pereira F. M. V., Milori D. M. B. P., Pereira-Filho E. R., et al. Computers and Electronics in Agric., 2011, 79: 90-93.

[10] Anne K. M., Erich C. O., et al. Eur J Plant Pathol, 2012, 133:197-209.

[11] Kumar A., Lee W. S., Ehsani R., et al. International Conference on Precision Agriculture, 2010.

[12] Pourreza A., Lee W. S. Ehsani R. et al. Computers and Electronics in Agriculture, 2015, 110: 221-232.

[13] TIAN Y. W., LI T. L., ZHANG L., et al. Transactions of the Chinese Society of Agricultural Engineering, 2010, 26(5): 202.

[14] XIE C. Q., WANG J. Y., FENG L., et al. Spectroscopy and Spectral Analysis, 2013, 33(6): 1603. 